\title{
LINFANGIOMA CÍSTICO DO MESENTÉRIO: UMA RARA APRESENTAÇÃO DE ABDÔMEN AGUDO
}

\author{
MESENTERIC CYSTIC LYMPHANGIOMA: AN UNCOMMON PRESENTATION \\ OF AN ACUTE ABDOMEN
}

\author{
Florentino de Araújo Cardoso Filho, TCBC-CE ${ }^{1}$ \\ Fábio Machado Landim² \\ Fernanda Braga Perdigão ${ }^{3}$
}

\section{INTRODUÇÃO}

Cisto do mesentério é afecção bastante rara. Desde sua primeira descrição em 1507 por Benevienae ${ }^{1,2}$ até 1993 há somente cerca de 820 casos relatados na literatura ${ }^{1}$.

Estima-se sua incidência em torno de 1:100.000 - 1:250.000 internamentos em adultos e 1:20.000 em crianças ${ }^{2}$.

\section{RELATO DO CASO}

Paciente do sexo feminino, 21 anos, com sintomatologia de quatro meses de dor em pontada e intermitente em quadrante superior esquerdo do abdômen, que teria se tornado mais intensa nos três dias que precederam seu internamento, quando percebeu massa móvel e dolorosa nessa topografia. Negava febre, calafrios, icterícia e emagrecimento.

Não há história de alcoolismo. Paciente apresentava bom estado geral. Ao exame físico constatava-se abdômen flácido, bastante doloroso em quadrante superior esquerdo, onde se palpava massa sólida de aproximadamente $8 \times 8 \mathrm{~cm}$, regular, pouco móvel, dolorosa, sem sinais de irritação peritoneal.

Amilase normal. Realizou ultra-sonografia abdominal que revelou volumosa massa expansiva cística no flanco esquerdo medindo $11 \times 9 \times 8 \mathrm{~cm}$, com ecos finos podendo traduzir líquido denso (hemorragia? pus?), sugestiva de cisto de mesentério. Não descartava possibilidade de cisto pancreático. Fez tomografia computadorizada do abdômen, que confirmou os achados da ultra-sonografia abdominal (Figura 1).

Foi submetida à laparotomia exploradora em 09/11/94, através de acesso mediano supra-umbilical, a qual encontrou volumoso cisto de mesentério, medindo aproximadamente 13 x $8 \mathrm{~cm}$, localizado em topografia de jejuno proximal logo após o ângulo duodeno-jejunal, de paredes espessas e conteúdo líquido denso, com grumos (Figura 2). Foram realizadas ressecção completa do cisto, sem enterectomia, e biópsia de linfonodos do mesentério e paraaórtico, que se encontravam aumentados de volume.

Teve ótima evolução recebendo alta hospitalar no quarto dia pós-operatório. O laudo histopatológico revelou tratar-se de cisto uniloculado, em cujas paredes são vistos espaços vasculares interpretáveis como linfáticos em associação com evidente exsudato inflamatório misto, podendo ser chamado linfangioma com inflamação crônica e hiperplasia reativa linfonodal.

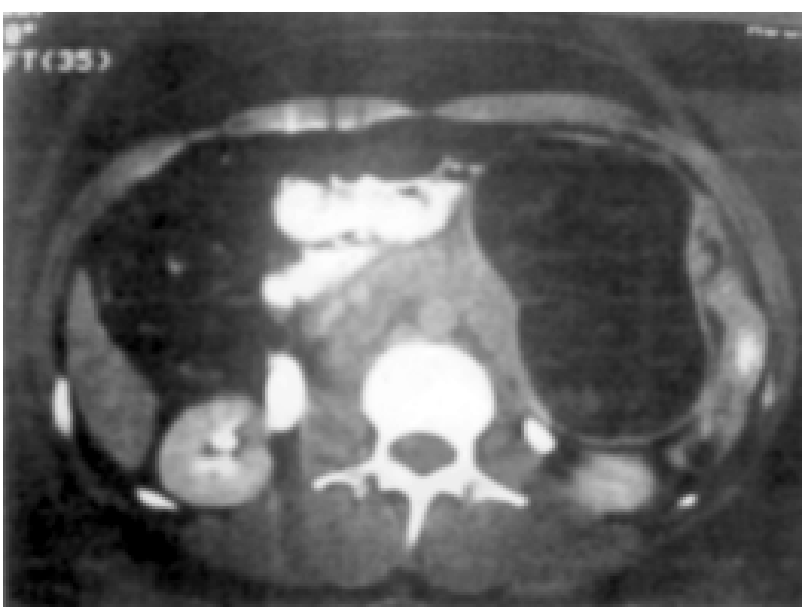

Figura 1 - Tomografia computadorizada do abdômen evidenciando lesão cística na porção superior do abdômen.

1. Professor e Mestre em Cirurgia do Departamento de Cirurgia da Faculdade de Medicina da Universidade Federal do Ceará. Preceptor da Residência Médica de Cirurgia Geral do Hospital Geral de Fortaleza.

2. Residente de Cirurgia Geral do Hospital Geral de Fortaleza.

3. Doutorando da Faculdade de Medicina da Universidade Federal do Ceará.

Recebido em 4/3/99

Aceito para publicação em 17/11/99

Trabalho realizado no Serviço de Cirurgia Geral do Hospital Geral de Fortaleza. 


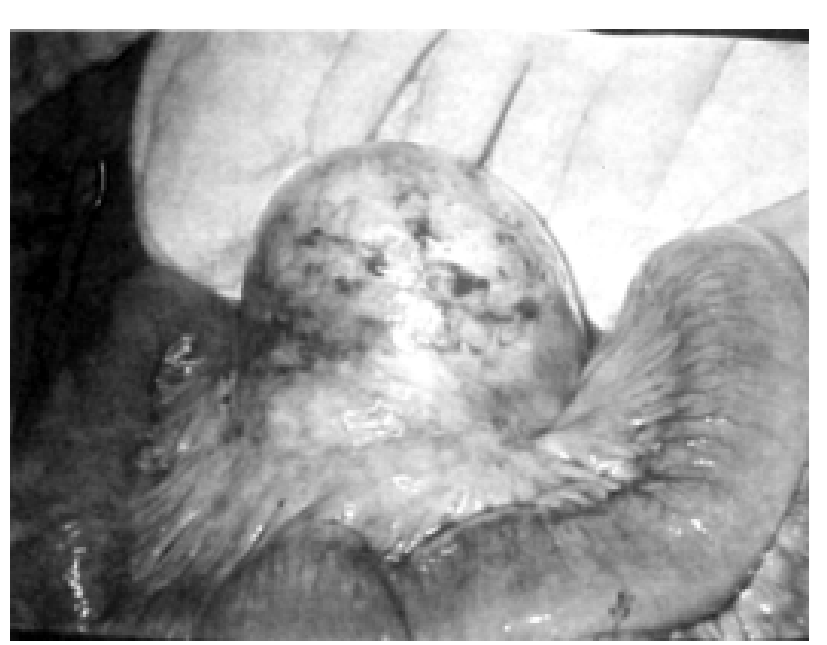

Figura 2 - Aspecto intra-operatório mostrando cisto do mesentério do jejuno proximal.

\section{DISCUSSÃO}

Cisto do mesentério foi primeiramente descrito em 1507 (apud Liew) pelo anatomista Benevienae. A primeira excisão foi realizada por Tillaux (apud Chung) somente em $1880^{2}$. Apesar do longo tempo do reconhecimento desta enfermidade, sua origem, classificação e patologia permanecem controversas. A maior incidência encontrase entre a terceira e quarta décadas de vida, sendo $75 \%$ dos casos diagnosticados após os 10 anos de idade ${ }^{2,3}$, com discreto predomínio do sexo feminino ${ }^{1}$.
Estas neoplasias císticas contidas no mesentério podem ser limitadas por células endoteliais ou mesoteliais ${ }^{3}$. Naqueles que predominam células endoteliais e que contêm fibras musculares ou tecido linfóide em sua cápsula são geralmente classificados como linfangioma cístico ${ }^{4}$. Podem acometer o mesentério do duodeno ao reto, sendo que $50 \%$ a $60 \%$ dos casos localizam-se na porção ileal. São histologicamente malignos em apenas 3\% dos casos.

Não há sinais e sintomas patognomônicos do cisto de mesentério ${ }^{2,5}$, o qual pode apresentar-se sob três aspectos: a) sintomas abdominais não específicos; b) achado incidental; c) abdômen agudo. A queixa mais comumente descrita pelos pacientes é de dor abdominal vaga, intermitente, associada a vômitos. Massa palpável ao exame físico ocorre em mais de $50 \%$ dos casos. São achados incidentais por ocasião de laparotomia ou exames de imagem em até $40 \%$ dos casos ${ }^{1}$. Abdômen agudo ocorre quando há ruptura, infecção, hemorragia ou torção do cisto, sendo eventualmente confundidos com apendicite aguda ou aneurisma de aorta.

Exames de laboratório pouco ajudam no diagnóstico. Raios X simples de abdômen podem evidenciar calcificações; arteriografia e trânsito intestinal podem evidenciar massa compressiva. Porém a ultra-sonografia, a tomografia computadorizada e a ressonância magnética são os exames que proporcionam melhor acuidade diagnóstica $^{3-5}$. Uma vez diagnosticado, todo cisto mesentérico deve ser ressecado, a fim de evitar suas complicações. A exérese completa é o tratamento de escolha ${ }^{4}$, sendo num pequeno número de casos necessária a enterectomia ${ }^{1}$. A drenagem interna pode ser uma opção quando há possibilidade de síndrome do intestino curto. Em casos selecionados a abordagem laparoscópica pode ser uma opção.

\begin{abstract}
Mesenteric cyst is a rare intra abdominal pathology. The incidence ranges from 1/100,000 to 1/250,000 hospital admissions. The authors present a case of a female patient, 20 years old, with abdominal pain for four months which three days had an acute onset of abdominal pain, and ultrasound revealed a cyst of mesentery within a dense fluid. The patient had been submitted to a laparotomy, and resection of the cyst. We emphasized the clinical symptoms, diagnostic evaluation and the therapeutic of this condition.
\end{abstract}

Key Words: Cystic lymphangioma; Mesenterium; Acute abdomen

\section{REFERÊNCIAS}

1. Liew SCC, Glenn DC, Storey DW - Mesenteric cyst. Aust. N.Z.J. Surg 1994; 64(11):741-744.

2. Chung MA, Brandt ML, St-Vil D et al. - Mesenteric cyst in children. J Pediat Surg 1991; 26(11):1306-8.

3. Bliss DP, Coffin CM, Bower RJ, et al - Mesenteric cyst in children. Surgery 1994; 115(5):571-7.

4. De Perrot M, Rostan O, Morel P et al. - Abdominal lymphangioma in adults and children. Brit J Surg 1998; 85: 395-7.
5. Vara-Thorbeck C, Méndez RT, Hidalgo RH, et al - Laparoscopy resection of a giant mesenteric cystic lymphangioma. Eur J Surg 1997; 163: 395-6.

\section{ENDEREÇO PARA CORRESPONDÊNCIA}

Dr. Florentino A. Cardoso Filho

Av. Rui Barbosa, 1435 - Aldeota

60115-221 Fortaleza - CE

E-mail:cardoso@roadnet.com 